\title{
Use of ambulatory blood pressure measurement in the definition of resistant hypertension: a review of the evidence
}

\begin{abstract}
Alexandre Persu ${ }^{1,2}$, Eoin O'Brien ${ }^{3}$ and Paolo Verdecchia ${ }^{4}$
Resistant hypertension as defined by the European Society of Hypertension and American Heart Association is a blood pressure that remains uncontrolled despite concomitant intake of at least three antihypertensive drugs (one of them preferably being a diuretic) at full doses. This definition is still based on office rather than out-of-office blood pressure measurement. In this review we propose a new, stricter definition of resistant hypertension based on ambulatory blood pressure measurement. The main arguments in favor of this are: (1) in patients with resistant hypertension, ambulatory blood pressure is an independent predictor of cardiovascular morbidity whereas, after adjustment for conventional risk factors, conventional blood pressure has little added value; (2) white-coat resistant hypertension (uncontrolled office with normal ambulatory blood pressure) is frequent (30-40\% of patients with apparently resistant hypertension) carrying a prognosis similar to that of controlled hypertension, and intensification of blood pressure lowering treatment, or the use of nondrug treatment strategies such as renal denervation or carotid baroreceptor stimulation, is not justified; (3) masked resistant hypertension (controlled office with elevated ambulatory blood pressure) is frequent (approximately one-third of patients with controlled office blood pressure on triple antihypertensive therapy) and associated with an increased risk of cardiovascular events; in such patients, treatment intensification should be considered; (4) the current definition of resistant hypertension (office blood pressure $\geqslant 140 / 90 \mathrm{~mm} \mathrm{Hg}$ on triple antihypertensive therapy) allows a substantial proportion of patients with spurious or white-coat resistant hypertension to undergo renal denervation in the absence of proven long-term benefits.
\end{abstract} Hypertension Research (2014) 37, 967-972; doi:10.1038/hr.2014.83; published online 17 April 2014

Keywords: ambulatory blood pressure; masked hypertension; renal denervation; resistant hypertension; white-coat hypertension

\section{INTRODUCTION}

Resistant hypertension (RHT) is a clinical situation in which blood pressure remains uncontrolled despite concomitant intake of at least three antihypertensive drugs (one of them preferably being a diuretic) at full doses. ${ }^{1}$ According to the American Heart Association, ${ }^{2}$ patients who require four drugs or more to have their blood pressure controlled are also considered as resistant. Depending on the populations studied and applied methods and definitions, the prevalence of RHT varies between 3 and $30 \%$ of the hypertensive population, ${ }^{3,4}$ with figures of $<10 \%$ probably representing the true prevalence. ${ }^{1}$ The diagnosis of RHT has important clinical implications, as patients with RHT more frequently present with secondary causes of hypertension, ${ }^{5}$ more severe target organ damage ${ }^{6}$ and increased risk of cardiovascular complications and death. ${ }^{7}$

Besides lifestyle and drug treatment optimization, alternative non-drug approaches such as renal sympathetic denervation ${ }^{8}$ and carotid baroreceptor stimulation ${ }^{9}$ have been recently proposed for the management of RHT. These new developments have put RHT to the forefront of the hypertension scene and raised controversies on the diagnosis and management of this subset of difficult-to-treat hypertensive patients. ${ }^{10-12}$ In particular, although some authors have stressed the importance of inclusion of out-of-office blood pressure measurements in the definition of RHT, ${ }^{10,13}$ recent guidelines such as those of the European Society of Hypertension ${ }^{1}$ are still based on office blood pressure measurement.

Compared with office measurement, ambulatory blood pressure measurement (ABPM) removes observer bias and measurement error, minimizes the white-coat effect and has greater reproducibility, and therefore provides a better estimate of a patient's usual blood pressure and cardiovascular prognosis. ${ }^{14-16}$ Self-measurement of blood pressure at home offers several of the well-recognized advantages of the more complex approach of ambulatory monitoring but it does not provide nocturnal blood pressure measurement. ${ }^{17,18}$ Current guidelines ${ }^{1,16,18,19}$ recommend one of these out-of-office modalities

${ }^{1}$ Pole of Cardiovascular Research, Institut de Recherche Expérimentale et Clinique, Université Catholique de Louvain, Brussels, Belgium; ${ }^{2}$ Division of Cardiology, Cliniques Universitaires Saint-Luc, Université Catholique de Louvain, Brussels, Belgium; ${ }^{3}$ The Conway Institute, University College Dublin, Dublin, Ireland and ${ }^{4}$ Department of Medicine, Hospital of Assisi, Assisi, Italy

Correspondence: Professor A Persu, Division of Cardiology, Cliniques Universitaires Saint-Luc (UCL), 10 Avenue Hippocrate, Brussels 1200 , Belgium.

E-mail: alexandre.persu@uclouvain.be

Received 18 January 2014; revised 7 March 2014; accepted 11 March 2014; published online 17 April 2014 
of automated blood pressure measurement as state-of-the-art modality in the management of hypertensive patients. Indeed, the case should be even more persuasive for RHT.

In order to address this important issue, this review summarizes current knowledge about the added value of out-of-office blood pressure measurement, and in particular ABPM in the specific context of RHT. In particular, it addresses the following questions: (1) what is the prevalence of white-coat and masked RHT?; (2) has white-coat RHT a different prognosis from RHT confirmed by ABPM?; (3) does ABPM improve risk stratification and prediction over and above conventional blood pressure in RHT?; and (4) are there reliable alternatives to ABPM to differentiate white-coat from true RHT?

\section{WHAT IS THE PREVALENCE OF WHITE-COAT AND MASKED RHT?}

White-coat RHT, defined as uncontrolled office blood pressure despite intake of at least three antihypertensive drugs but normal ambulatory blood pressure, has been diagnosed in 20 to $40 \%$ of patients with apparently RHT. ${ }^{20-24}$ In a large Spanish ABPM registry of treated hypertensive patients $(n=68045),{ }^{6} 37.5 \%$ of 8295 patients with apparently RHT had normal 24-h ABPM $(<130 / 80 \mathrm{~mm} \mathrm{Hg})$. According to a recent update of the same database ${ }^{25}$ (14 461 patients with RHT, including patients on 4 antihypertensive drugs or more, irrespective of office blood pressure values), the proportion of patients with white-coat RHT was $40.1 \%$ according to 24 -h blood pressure criteria $(<130 / 80 \mathrm{~mm} \mathrm{Hg}), 47.3 \%$ by daytime blood pressure criteria $(<135 / 85 \mathrm{~mm} \mathrm{Hg})$ and $33.4 \%$ by nighttime blood pressure criteria $(<120 / 70 \mathrm{~mm} \mathrm{Hg})$. In the same study, ${ }^{25}$ the prevalence of masked RHT (uncontrolled ambulatory blood pressure despite concomitant intake of three antihypertensive drugs, but controlled office blood pressure) was $31.0 \%$, for $24-\mathrm{h}, 23.6 \%$ for diurnal and $41.7 \%$ for nocturnal pressures.

\section{Conclusion}

The prevalence of white-coat RHT is in the range of 35-40\%. Masked RHT is less studied but may be observed in one-third of hypertensive patients with office blood pressure controlled while on three antihypertensive drugs or more.

\section{HAS WHITE-COAT RHT A DIFFERENT PROGNOSIS FROM RHT CONFIRMED BY ABPM?}

Several cross-sectional studies have shown a higher prevalence of target organ damage in patients with white-coat vs. true RHT (that is, elevated office and 24-h ambulatory blood pressure). In a cohort of 286 patients with RHT, patients with true RHT $(n=161)$ suffered more often from nephropathy ( 40.1 vs. $23.9 \%, P=0.007)$ and tended to have more left ventricular hypertrophy (83.3 vs. $76.3, P=0.05$ ) than their counterparts with white-coat RHT $(n=125) .{ }^{26}$ In the Spanish ABPM registry, ${ }^{6}$ patients with RHT confirmed by ABPM had a worse cardiovascular risk profile, including higher proportions of smokers ( $15 \%$ vs. $10 \%)$, diabetics ( $35 \%$ vs. $28 \%)$, left ventricular hypertrophy as detected by electrocardiogram (19\% vs. $14 \%)$, microalbuminuria $(30 \%$ vs. $20 \%)$ and previous cardiovascular disease $(19 \%$ vs. $16 \%$; all comparisons $P<0.001)$. In multivariable analysis, true RHT was associated with younger age, male sex, longer duration of hypertension, smoking, diabetes, elevated plasma creatinine and a history of previous cardiovascular disease $(P<0.05){ }^{6}$

Although cross-sectional studies suggest a higher risk of true $v s$. white-coat RHT, a definitive figure is dependent on data from prospective studies. Pierdomenico et al. ${ }^{27}$ evaluated the incidence of cardiovascular events in 742 treated hypertensive patients (340 with controlled hypertension according to both office and ABPM, 126 with masked hypertension, 146 with white-coat RHT and 130 with true RHT). In agreement with previous studies, at baseline, prevalence of left ventricular hypertrophy, diabetes, heavy smokers $(\geqslant 20$ cigarettes/ day) and serum creatinine levels were higher in patients with true RHT compared with controlled and white-coat resistant hypertension. During the follow-up period (4.98 \pm 2.9 years), 109 patients reached the primary composite end point. The event rate per 100 patient-years in subgroups with controlled, masked, white-coat resistant and true RHT was $0.87,2.42,1.2$ and 4.1, respectively (Figure 1). After adjustment for several covariates, including conventional blood pressure, the incidence of cardiovascular events was significantly higher in masked hypertension (relative risk: 2.28, $P<0.05)$ and in true RHT $(2.94, P<0.05)$ vs. controlled hypertension, whereas there was no significant difference between white-coat RHT and controlled hypertension. ${ }^{27}$

In a prospective study of 436 hypertensive patients with chronic kidney disease stages II to V (mean estimated glomerular filtration rate: $43 \mathrm{ml} \mathrm{min}^{-1}$ per $1.73 \mathrm{~m}^{2}$ ) attending 4 outpatients nephrology clinics in Italy, ${ }^{28}$ four groups were defined by combining ABPM data with diagnosis of RHT (office blood pressure $\geqslant 130 / 80 \mathrm{~mm} \mathrm{Hg}$, despite prescription of $\geqslant 3$ full-dose antihypertensive drugs including a diuretic or $\geqslant 4$ drugs): controlled $(27.1 \%, 24 \mathrm{~h}-\mathrm{ABPM}$
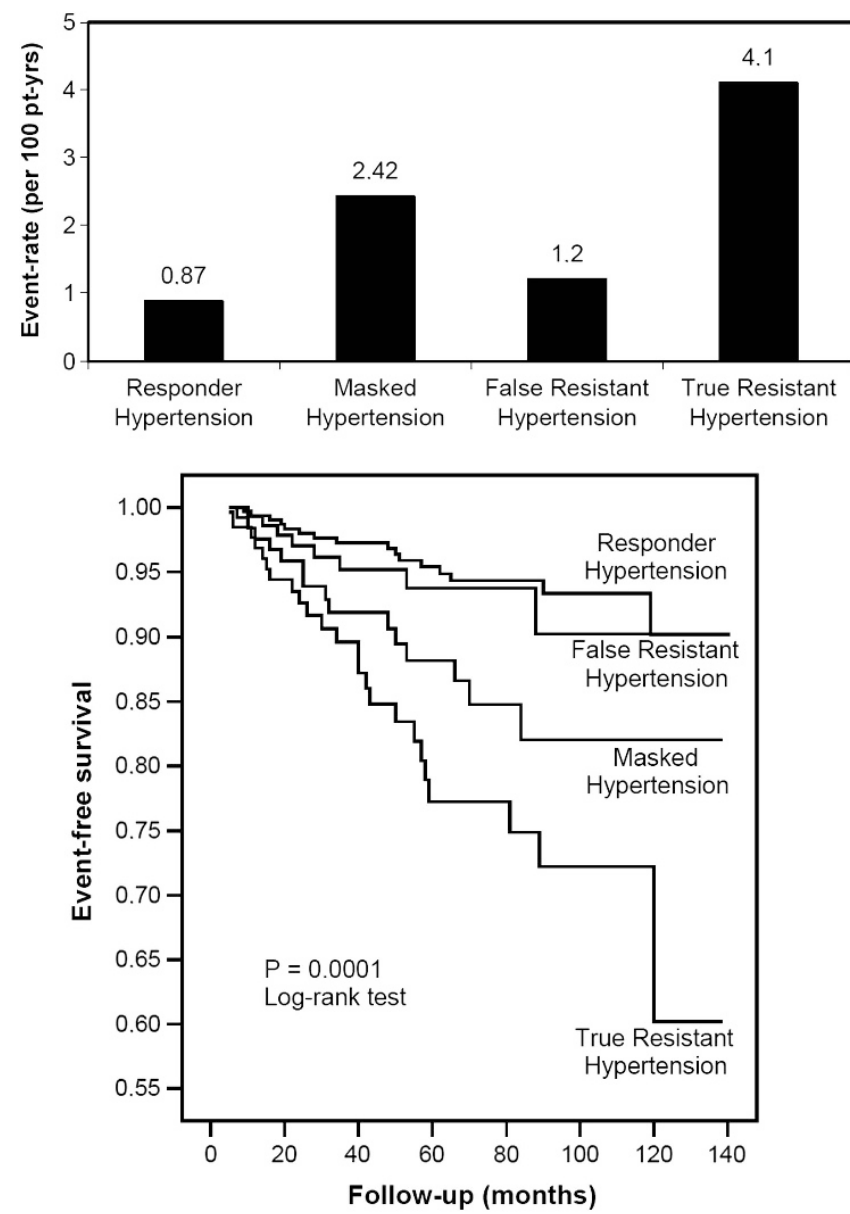

Figure 1 Event-rates per 100 patients-years (pt-yrs) (top) and event-free survival curves (bottom) in subjects with responder, masked, false (whitecoat) resistant hypertension and true resistant hypertension (taken from Pierdomenico et al. ${ }^{27}$ with permission). 
$<125 / 75 \mathrm{~mm} \mathrm{Hg}$ without RHT); white-coat RHT (7.1\%; 24 h-ABPM $<125 / 75 \mathrm{~mm} \mathrm{Hg}$ with RHT); sustained hypertension (42.9\%, $24 \mathrm{~h}$ $\mathrm{ABPM} \geqslant 125 / 75 \mathrm{~mm} \mathrm{Hg}$ without RHT); and true resistance (22.9\%, $24 \mathrm{~h}-\mathrm{ABPM} \geqslant 125 / 75 \mathrm{~mm} \mathrm{Hg}$ with RHT). Significant baseline correlates of true $\mathrm{RH}$ were diabetes (odds ratio: 2.84, 95\% confidence interval (CI): 1.68-4.77), left ventricular hypertrophy (odds ratio: 2.32, 95\% CI: 1.23-4.38), higher proteinuria levels (odds ratio: $2.31,95 \%$ CI: $1.49-3.58$ ) and poor adherence to lowsalt diet (odds ratio: 2.15, 95\% CI: 1.06-4.38). ${ }^{28}$ End points of survival analysis were renal (end-stage renal disease or death) and cardiovascular events (fatal and nonfatal cardiovascular event). Over 57 months of median follow-up, 109 cardiovascular events and 165 renal events occurred. Compared with controlled patients, the hazard ratios of cardiovascular (1.98; 95\% CI: 1.14-3.43) and renal events (2.66; 95\% CI: 1.62-4.37) were significantly increased in patients with true RHT, but not in the subset with white-coat RHT. The hazard ratio of sustained hypertension was significantly increased for renal (hazard ratio: $2.14 ; 95 \%$ CI: $1.35-3.40$ ) but not cardiovascular events. $^{28}$

\section{Conclusion}

Compared with white-coat RHT, true RHT is more frequently associated with other cardiovascular risk factors and target organ damage. Furthermore, true RHT is an independent predictor of cardiovascular and renal morbidity, whereas the prognosis of whitecoat RHT does not differ from that of controlled hypertension. In contrast, masked RHT is associated with an increased risk of cardiovascular and renal events.

\section{DOES ABPM IMPROVE RISK STRATIFICATION AND PREDICTION OVER AND ABOVE CONVENTIONAL BLOOD PRESSURE IN RHT?}

Redon et al. ${ }^{29}$ prospectively followed 86 essential hypertensive patients whose diastolic blood pressure remained $>100 \mathrm{~mm} \mathrm{Hg}$ on triple antihypertensive therapy including a diuretic for a median duration of 49 months (range: 6-96). End-organ damage and cardiovascular events were monitored yearly and incorporated in a score of cardiovascular damage. Patients were divided into tertiles of average diastolic blood pressure according to ABPM, with the lowest tertile $<88 \mathrm{~mm} \mathrm{Hg}$, the middle tertile $88-97 \mathrm{~mm} \mathrm{Hg}$ (and the highest tertile $>97 \mathrm{~mm} \mathrm{Hg}$. A progression in the end-organ damage score was observed for the highest tertile group but not for the two other groups. Twenty-one patients had a new cardiovascular event; the incidence of events was significantly lower for the lowest tertile group (2.2 per 100 patient-years) than it was for the middle tertile group ( 9.5 per 100 patient-years) or for the highest tertile group (13.6 per 100 patient-years). The probability of event-free survival was also significantly different when comparing the lowest tertile group with the other two groups. Belonging to the highest blood pressure tertile was an independent risk factor for the incidence of cardiovascular events (relative risk, 6.20; 95\% CI: $1.38-28.1 ; P<0.02$ ). ${ }^{29}$

Salles et al. ${ }^{22}$ prospectively followed 556 apparently RHT patients for a median of 4.8 years. Of these patients, 109 (19.6\%) reached the primary end point, and 70 all-cause deaths (12.6\%) occurred (46 had cardiovascular causes). After adjustment for sex, age, body mass index, diabetes mellitus, smoking, physical inactivity, dyslipidemia, previous cardiovascular diseases, serum creatinine level and number of antihypertensive drugs, no office blood pressure showed any prognostic value. After adjustment for the same variables and office blood pressure, higher mean ambulatory blood pressures were independent predictors of the composite end point. The hazard ratios associated with a 1-s.d. increment in daytime and nighttime systolic blood pressure were 1.26 and 1.38, respectively; the corresponding values for diastolic blood pressure were 1.31 and 1.36. ${ }^{22}$ In agreement with previous studies, ${ }^{27}$ the diagnosis of true $\mathrm{RH}$ was an independent predictor of the composite end point (fully adjusted hazard ratio of 2.11) but also of all-cause mortality (hazard ratio of 2.0). Finally, on Kaplan-Meier analysis, the diagnosis of true or white-coat RH distinguished two subgroups of patients with significantly different prognoses regarding the occurrence of any cardiovascular event (Figure 2) and of all-cause and cardiovascular mortalities. ${ }^{22}$ Ambulatory systolic and diastolic blood pressure values were equivalent predictors, and nighttime blood pressure was superior to daytime blood pressure. ${ }^{22}$

\section{Conclusion}

In patients with RHT, higher ambulatory blood pressures were associated with an increased risk of cardiovascular morbidity. After adjustment for sex, age and conventional risk factors, office blood pressure had no predictive value whatsoever in patients with RHT.

\section{ARE THERE RELIABLE ALTERNATIVES TO ABPM TO DIFFERENTIATE WHITE-COAT FROM TRUE RHT?}

Based on previous knowledge on the demographic characteristics and risk profile of patients with RHT confirmed by ABPM, Muxfeldt et $a .^{21}$ developed a scoring system likely to detect true RHT without use of out-of-office blood pressure measurement. Despite a high positive predictive value $(90 \%)$, the latter could not be recommended for clinical practice because of a low sensitivity (32\%) and high rate of misclassification (40\%). ${ }^{30}$ Given its wider availability, acceptability and lower cost, home blood pressure measurement may appear to be a reasonable alternative to ABPM. However, despite improving technology to provide nocturnal blood pressure, ${ }^{31,32}$ the technique generally does not provide a measure of nighttime blood pressure, which has a higher predictive value than daytime blood pressure, both in the general population ${ }^{16}$ and in $\mathrm{RHT}^{22}$

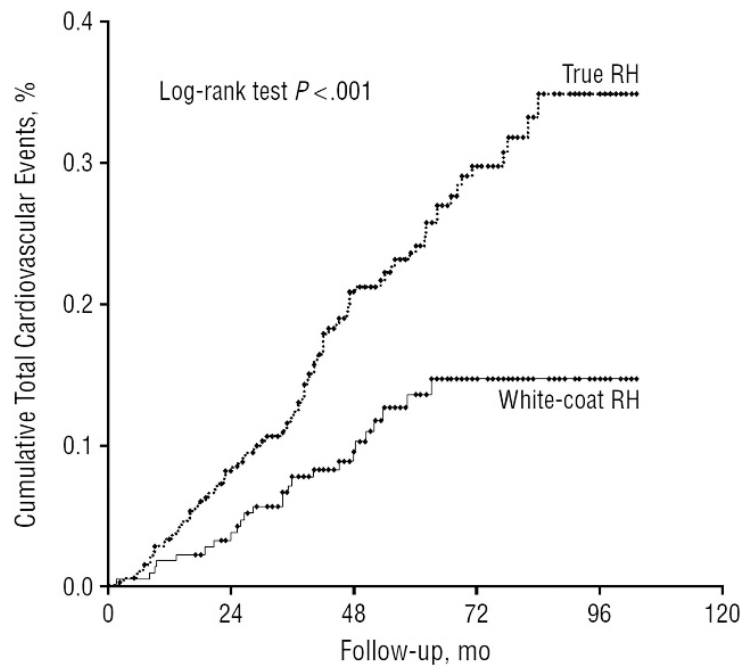

No. of patients at risk

$\begin{array}{lrrrrr}\text { True RH } & 338 & 300 & 200 & 93 & 14 \\ \text { White-coat RH } & 218 & 203 & 136 & 44 & 9\end{array}$

Figure 2 Kaplan-Meier estimates of incident total fatal and nonfatal cardiovascular event curves in patients grouped according to ambulatory blood pressure monitoring diagnosis of true or white-coat resistant hypertension $(\mathrm{RH})$ (taken from Salles et al. ${ }^{22}$ with permission). 
In a Japanese cohort including 528 patients taking three or more antihypertensive drugs assessed by conventional and home blood pressure measurement, ${ }^{33}$ white-coat RHT (office blood pressure $\geqslant 140 / 90 \mathrm{mmHg}$; home blood pressure $<135 / 85 \mathrm{~mm} \mathrm{Hg}$ ) was found in $16.1 \%$ of patients and masked RHT (office blood pressure $<140 / 90 \mathrm{~mm} \mathrm{Hg}$; home blood pressure $\geqslant 135 / 85 \mathrm{~mm} \mathrm{Hg}$ ) in $23.5 \%$. Unfortunately however, ABPM data were not available. Only two studies $^{34,35}$ compared the relative performance of both home and ABPM out-of-office blood pressure measurements. In the first studt, ${ }^{34}$ a small cohort including 51 RHT patients, reasonable correlations were found between daytime ambulatory blood pressure and home systolic and $(r=0.70)$ and diastolic blood pressure $(r=0.69)$. The second study ${ }^{35}$ included 73 patients on stable treatment with three or more antihypertensive drugs. Uncontrolled blood pressure was defined as blood pressure $\geqslant 140 / 90 \mathrm{~mm} \mathrm{Hg}$ for office blood pressure and blood pressure $\geqslant 135 / 85 \mathrm{~mm} \mathrm{Hg}$ for daytime ABPM and home blood pressure. Both out-of-office blood pressure methods agreed on the diagnosis of truly resistant, white-coat and masked RHT in 74\%

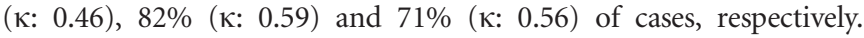
Compared with ABPM, the specificity of home blood pressure for the detection of white-coat RHT was high (93\%) but the sensitivity was unacceptably low (63\%). Notably, in these two studies, home blood pressure was compared with daytime ambulatory blood pressure. Correlations between home and $24 \mathrm{~h}$-ambulatory blood pressure, which is used for the definition of white-coat and masked hypertension, would probably prove even weaker, further limiting the value of home blood pressure in assessing RHT. Finally, the predictive value of home blood pressure has not been studied in patients with RHT.

\section{Conclusion}

Attempts to develop a score predicting true RHT without using out-of-office blood pressure measurements proved unsuccessful. Home blood pressure measurement is a potential alternative to ABPM. However, few comparisons have been made between the relative performance of both out-of-office blood pressure measurements in RHT. Furthermore, home blood pressure does not incorporate information on nighttime blood pressure and its predictive value in RHT has not been studied thus far. Therefore, on current evidence, ABPM remains the gold standard for blood pressure assessment in RHT.

\section{ABPM IS ESSENTIAL FOR THE DIAGNOSIS AND MANAGEMENT OF PATIENTS WITH RESISTANT HYPERTENSION}

As shown above, white-coat RHT is frequent ${ }^{6,25}$ and has a prognosis similar to that of controlled hypertension..$^{22,27,28}$ Accordingly, there is no indication to intensify antihypertensive treatment in patients with white-coat RHT. In these patients, the use of ABPM may prevent overtreatment and, consequently, drug adverse effects and poor adherence to therapy ${ }^{30}$ and possibly ischemia-induced worsening of cardiorenal damage. ${ }^{28}$ ABPM also allows identification of patients with masked RHT, characterized by a poor cardiovascular prognosis, ${ }^{27}$ in whom treatment intensification may be indicated. Furthermore, ABPM is an independent predictor of cardiovascular events in RHT, while in the study of Salles et al., ${ }^{22}$ office blood pressure had no predictive value whatsoever. Finally, ABPM provides important information to guide the time schedule of drug intake in patients with difficult-to-treat and resistant hypertension ${ }^{36}$ and to assess blood pressure control after witnessed drug intake when poor compliance is suspected. ${ }^{37,38}$ Accordingly, 13 of 14 international guidelines issued from 2000 to 2013 agreed on the fact that ABPM is indicated to identify patients with resistant hypertension. ${ }^{16}$ In particular, American ${ }^{19}$ and European ${ }^{1}$ hypertension guidelines, as well as the recent position paper on ABPM issued by the European Society of Hypertension, ${ }^{16}$ recognize 'identification of true and false resistant hypertension' as an indication of ABPM and recommend ABPM as an essential tool in the diagnosis, management and follow-up of patients with RHT.

\section{EVALUATION OF NEW DRUGS OR INTERVENTIONS IN RHT SHOULD BE BASED ON AMBULATORY RATHER THAN OFFICE BLOOD PRESSURE MEASUREMENT}

As the prognosis of patients with white-coat RHT is similar to that of controlled patients without $\mathrm{RHT}^{22,27}$ it is not justified and even unethical to include such patients in trials testing new drugs or interventions in RHT, which will be the case if inclusion is based on office blood pressure rather than ABPM. In addition, if participants are enrolled based on office blood pressure influenced by the whitecoat phenomenon, their true (lower) blood pressure values are less likely to be reduced by the intervention, thereby lessening the likelihood of finding compelling evidence that the intervention is effective. ${ }^{39}$ Finally, using ambulatory rather than office blood pressure criteria to determine eligibility has the advantage of allowing inclusion of patients with masked RHT who are currently excluded from most trials because of controlled office blood pressure, despite an increased cardiovascular risk. ${ }^{27}$

Furthermore, as ambulatory but not office blood pressure is an independent predictor of cardiovascular morbidity in $\mathrm{RHT},{ }^{22}$ the primary end point of trials in patients with RHT should be based on ambulatory and not office blood pressure measurement. This is of particular importance in observational, nonrandomized trials in order to limit white-coat effect and observer-related biases. The latter include the tendency to repeat measures considered erroneously high in the intervention group, but not in the control group, ${ }^{40}$ thus leading to an underestimation of the final blood pressure values in the intervention group, a phenomenon likely to explain part of the wide discrepancy between office and ambulatory blood pressure decrease in renal denervation trials. ${ }^{40}$

Notably, after a first promising study, ${ }^{41}$ the development of the endothelin receptor antagonist Darusentan as an antihypertensive drug was stopped, because in a second randomized trial, ${ }^{42}$ it failed to show superiority over placebo for change in office systolic blood pressure from baseline to week 14. Nevertheless, the decrease in ambulatory blood pressure was significant $(\sim-10 /-8 \mathrm{~mm} \mathrm{Hg})^{42}$ and similar to that observed in the pivotal trial. ${ }^{41}$ The authors regretted having used office rather than ambulatory blood pressure as primary end point and stated that 'future hypertension trials should seriously consider using change in ambulatory blood pressure, rather than office blood pressure, as the primary endpoint. ${ }^{42}$ Turner and $\mathrm{O}^{\prime}$ Brien $^{39}$ made an even stronger statement, saying that ABPM is the most appropriate and informative methodology and should be mandatory in all studies testing new drug or nondrug interventions in RHT, both for patient recruitment and for evaluation of the intervention's potential benefits.

The overwhelming evidence in favor of the superiority of ABPM over office blood pressure, particularly in RHT, did not however deter the authors of the Symplicity HTN-2 trial, ${ }^{8}$ choosing office rather than ambulatory blood pressure measurement as primary end point. Furthermore, although 15000 to 20000 renal denervation procedures may have been performed worldwide ${ }^{38}$ and the procedure is reimbursed in several European countries, mostly based on this 
trial, $^{8}$ white-coat RHT was not an exclusion criterion, baseline ambulatory blood pressure values were not reported and ambulatory blood pressure decrease at 6 months was reported in $<50 \%$ of patients. ${ }^{10}$ Finally, the Symplicity HTN-2 study ${ }^{8}$ may have been particularly vulnerable to observer-related bias. Indeed, the protocol (version 4 April 2009) instructed investigators: (1) to measure office blood pressure at least 3 times; (2) to take additional measurements until they were consistent within $5 \mathrm{~mm} \mathrm{Hg}$; (3) and to record three consistent readings on the case report forms. The number of readings required to reach consistency and those selected to be recorded on the patient forms (consecutive or not) are not in the public domain. The number of repetitions might thus have been different between randomized groups, particularly at the time of the assessment of the primary end point. ${ }^{10}$

Subsequent observational trials in renal denervation were also based on conventional rather than ambulatory blood pressure. ${ }^{43}$ Ambulatory blood pressure changes after renal denervation were seldom reported and, when available, not always significant, ${ }^{44}$ notably in patients with normal ambulatory blood pressure at baseline. ${ }^{45}$ Although patients with white-coat RHT are now considered ineligible for renal denervation according to both European ${ }^{46}$ and international ${ }^{47}$ recommendations, the primary end point of most ongoing trials, including Symplicity HTN-3 (NCT01418261), ${ }^{48}$ is still based on conventional blood pressure.

Similarly, the pivotal trial evaluating the efficacy of carotid baroreceptor stimulation in $\mathrm{RHT}^{9}$ was focused on conventional blood pressure and, more than 2 years after publication, ABPM values remain unpublished. This is a matter of particular concern in view of the wide discrepancy between office and ambulatory blood pressure decreases in renal denervation trials (ratio of $30 \%$ vs. an expected $60-70 \%$ in drug trials) $)^{10,49,50}$ (Figure 3), likely explained by an overinflation of conventional blood pressure results reflecting Hawthorne effect, regression to the mean and observer-related biases. ${ }^{40}$

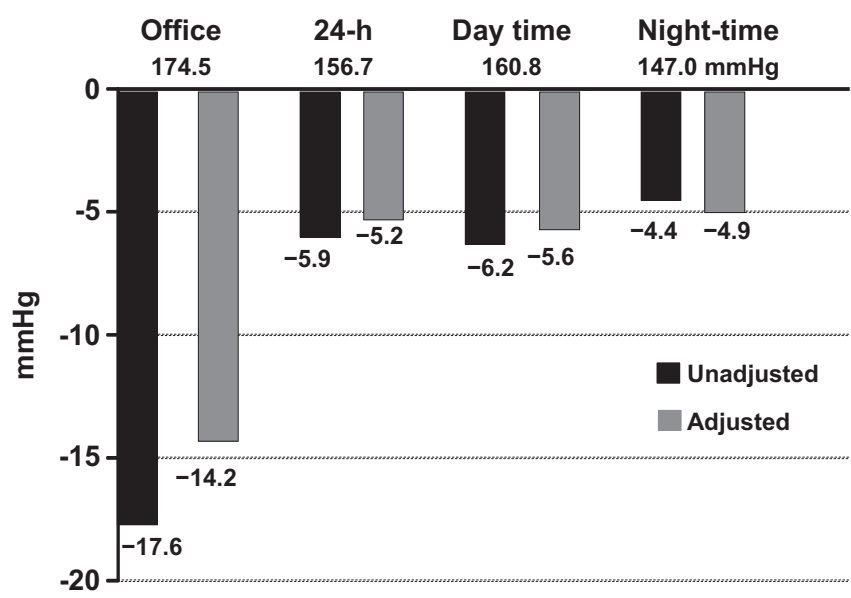

Figure 3 Mean office and ambulatory blood pressure decrease 6 months after renal denervation in 109 patients with resistant hypertension included in the European Network Coordinating research on REnal Denervation (ENCOReD) Consortium. $X$ axis: office and ambulatory blood pressure $(\mathrm{mm} \mathrm{Hg})$ at baseline. $Y$ axis: blood pressure decrease 6 months after renal denervation, with (gray) and without (black) adjustment for baseline blood pressure and center. $P$-values of $<0.05$ for unadjusted nighttime blood pressure decrease and $<0.01$ for all other changes (Persu et al. ${ }^{50}$ ).

\section{ABPM SHOULD BE INCLUDED IN THE DEFINITION OF RESISTANT HYPERTENSION}

Although the European ${ }^{1}$ and American ${ }^{2,19}$ hypertension guidelines acknowledge the importance of ABPM for the diagnosis, risk stratification and management of RHT, the definition is still based on office blood pressure measurement that is not an independent predictor of cardiovascular events in this condition. ${ }^{22}$ This leads to the introduction of confusing entities as 'apparently resistant' hypertension, 'resistant but controlled' and 'false' vs. 'true resistant' hypertension ${ }^{13}$ and, more importantly, to unjustified and potentially harmful treatment intensification in patients with white-coat RHT and undertreatment in patients with masked RHT. Furthermore, it provides an additional justification for manufacturers of renal denervation systems to support trials with a suboptimal design and promote further diffusion of the technique in all patients with uncontrolled blood pressure despite prescription of three antihypertensive drugs, ${ }^{10,13}$ in the absence of evidence of long-term benefits on hard end points. Accordingly, we make a strong statement in favor of a new, more stringent definition of RHT including out-ofoffice blood pressure measurement, preferably ABPM, as is already the case for the National Institute for Health and Care Excellence (NICE) guidelines ${ }^{51}$ and the recent consensus on RHT of the French Society of Hypertension. ${ }^{52}$

1 Mancia G, Fagard R, Narkiewicz K, Redon J, Zanchetti A, Bohm M, Christiaens T, Cifkova R, De BG, Dominiczak A, Galderisi M, Grobbee DE, Jaarsma T, Kirchhof P, Kjeldsen SE, Laurent S, Manolis AJ, Nilsson PM, Ruilope LM, Schmieder RE, Sirnes PA, Sleight P, Viigimaa M, Waeber B, Zannad F. 2013 ESH/ESC Guidelines for the management of arterial hypertension: the Task Force for the management of arterial hypertension of the European Society of Hypertension (ESH) and of the European Society of Cardiology (ESC). J Hypertens 2013; 31: 1281-1357.

2 Calhoun DA, Jones D, Textor S, Goff DC, Murphy TP, Toto RD, White A, Cushman WC, White W, Sica D, Ferdinand K, Giles TD, Falkner B, Carey RM. Resistant hypertension: diagnosis, evaluation, and treatment. A scientific statement from the American Heart Association Professional Education Committee of the Council for High Blood Pressure Research. Hypertension 2008; 51: 1403-1419.

3 Staessen JA, Kuznetsova T, Stolarz K. Hypertension prevalence and stroke mortality across populations. JAMA 2003; 289: 2420-2422.

4 Hayek SS1, Abdou MH, Demoss BD, Legaspi JM, Veledar E, Deka A, Krishnan SK, Wilmot KA, Patel AD, Kumar VR, Devireddy CM. Prevalence of resistant hypertension and eligibility for catheter-based renal denervation in hypertensive outpatients. $\mathrm{Am} \mathrm{J}$ Hypertens 2013; 26: 1452-1458.

5 Pedrosa RP, Drager LF, Gonzaga CC, Sousa MG, de Paula LK, Amaro AC, Amodeo C, Bortolotto LA, Krieger EM, Bradley TD, Lorenzi-Filho G. Obstructive sleep apnea: the most common secondary cause of hypertension associated with resistant hypertension. Hypertension 2011; 58: 811-817.

6 de la Sierra A, Segura J, Banegas JR, Gorostidi M, de la Cruz JJ, Armario P, Oliveras A, Ruilope LM. Clinical features of 8295 patients with resistant hypertension classified on the basis of ambulatory blood pressure monitoring. Hypertension 2011; 57: 898-902.

7 Daugherty SL, Powers JD, Magid DJ, Tavel HM, Masoudi FA, Margolis KL, O'Connor PJ, Selby JV, Ho PM. Incidence and prognosis of resistant hypertension in hypertensive patients. Circulation 2012; 3: 1635-1642.

8 Esler MD, Krum H, Sobotka PA, Schlaich MP, Schmieder RE, Bohm M. Renal sympathetic denervation in patients with treatment-resistant hypertension (The Symplicity HTN-2 Trial): a randomised controlled trial. Lancet 2010; 376: 1903-1909.

9 Bisognano JD, Bakris G, Nadim MK, Sanchez L, Kroon AA, Schafer J, de Leeuw PW, Sica DA. Baroreflex activation therapy lowers blood pressure in patients with resistant hypertension: results from the double-blind, randomized, placebo-controlled rheos pivotal trial. J Am Coll Cardiol 2011; 58: 765-773.

10 Persu A, Renkin J, Thijs L, Staessen JA. Renal denervation: ultima ratio or standard in treatment-resistant hypertension. Hypertension 2012; 60: 596-606.

11 Schlaich MP, Esler MD, Fink GD, Osborn JW, Euler DE. Targeting the sympathetic nervous system: critical issues in patient selection, efficacy, and safety of renal denervation. Hypertension 2013; 63: 426-432.

12 Taddei S, Bruno RM. Renal denervation: still more questions than answers. J Hypertens 2014; 32: 28-29.

13 Campese VM. Interventional hypertension: a new hope or a new hype? The need to redefine resistant hypertension. J Hypertens 2013; 31: 2118-2121.

14 Kikuya M, Hansen TW, Thijs L, Björklund-Bodegård K, Kuznetsova T, Ohkubo T, Richart T, Torp-Pedersen C, Lind L, Ibsen H, Imai Y, Staessen JAon behalf of the International Database on ambulatory blood pressure in relation to Cardiovascular 
Outcome (IDACO) investigators. Diagnostic thresholds for ambulatory blood pressure monitoring based on 10-year cardiovascular risk. Circulation 2007; 115: 2145-2152.

15 Hansen TW, Kikuya M, Thijs L, Björklund-Bodegård K, Kuznetsova T, Ohkubo T, Richart T, Torp-Pedersen C, Lind L, Jeppesen J, Ibsen H, Imai Y, Staessen JAon behalf of the IDACO Investigators. Prognostic superiority of daytime ambulatory over conventional blood pressure in four populatios: a meta-analysis of 7030 individuals. J Hypertens 2007; 25: 1554-1564.

16 O'Brien E, Parati G, Stergiou G, Asmar R, Beilin L, Bilo G, Clement D, de la Sierra A, de LP, Dolan E, Fagard R, Graves J, Head GA, Imai Y, Kario K, Lurbe E, Mallion JM, Mancia G, Mengden T, Myers M, Ogedegbe G, Ohkubo T, Omboni S, Palatini $P$, Redon J, Ruilope LM, Shennan A, Staessen JA, vanMontfrans G, Verdecchia $P$, Waeber B, Wang J, Zanchetti A, Zhang Y. European Society of Hypertension position paper on ambulatory blood pressure monitoring. J Hypertens 2013; 31: 1731-1768.

17 Staessen JA, Thijs L, Ohkubo T, Kikuya M, Richart T, Boggia J, Adiyaman A, Dechering DG, Kuznetsova T, Thien T, de Leeuw P, Imai Y, O'Brien E, Parati G. Thirty years of research on diagnostic and therapeutic thresholds for the self-measured blood pressure at home. Blood Press Monit 2008; 13: 352-365.

18 Pickering TG, Houston Miller N, Ogedegbe G, Krakoff LR, Artinian NT, Goff D. Call to action on use and reimbursement for home blood pressure monitoring. A joint scientific statement from the American Heart Association, American Society of Hypertension, and Preventive Cardiovascular Nurses Association. Hypertension 2008; 52: 10-29.

19 Chobanian AV, Bakris GL, Black BK, Cushman WC, Green LA, Izzo JL Jr., Jones DW, Materson BJ, Oparil S, Wright JT Jr., Roccella EJand the National High Blood Pressure Education Program Coordinating Committee. Seventh report of the Joint National Committee on Prevention, Detection, Evaluation, and Treatment of High Blood Pressure. Hypertension 2003; 42: 1206-1252.

20 Brown MA, Buddle ML, Martin A. Is resistant hypertension really resistant? Am J Hypertens 2001; 14: 1263-1269.

21 Muxfeldt ES, Bloch KV, Nogueira AR, Salles GF. True resistant hypertension: is it possible to be recognized in the office? Am J Hypertens 2005; 18: 1534-1540.

22 Salles GF, Cardoso CR, Muxfeldt ES. Prognostic influence of office and ambulatory blood pressures in resistant hypertension. Arch Intern Med 2008; 168: 2340-2346.

23 Oliveras A, Armario P, Hernández-Del Rey R, Arroyo JA, Poch E, Larrousse M, RocaCusachs $A$, de la Sierra A. Urinary albumin excretion is associated with true resistant hypertension. J Hum Hypertens 2010; 24: 27-33.

24 Brambilla G, Bombelli M, Seravalle G, Cifkova R, Laurent S, Narkiewicz K, Facchetti R, Redon J, Mancia G, Grassi G. Prevalence and clinical characteristics of patients with true resistant hypertension in central and Eastern Europe: data from the BP-CARE study. J Hypertens 2013; 31: 2018-2024.

25 de la Sierra A, Banegas JR, Oliveras A, Gorostidi M, Segura J, de la Cruz JJ, Armario P, Ruilope LM. Clinical differences between resistant hypertensives and patients treated and controlled with three or less drugs. J Hypertens 2012; 30: 1211-1216.

26 Muxfeldt ES, Bloch KV, Nogueira AR, Salles GF. Twenty-four hour ambulatory blood pressure monitoring pattern of resistant hypertension. Blood Press Monit 2003; 8 $181-185$.

27 Pierdomenico SD, Lapenna D, Bucci A, Di TR, Di MR, Manente BM, Caldarella MP, Neri M, Cuccurullo F, Mezzetti A. Cardiovascular outcome in treated hypertensive patients with responder, masked, false resistant, and true resistant hypertension. Am J Hypertens 2005; 18: 1422-1428.

28 De Nicola L, Gabbai FB, Agarwal R, Chiodini P, Borrelli S, Bellizzi V, Nappi F, Conte G, Minutolo R. Prevalence and prognostic role of resistant hypertension in chronic kidney disease patients. J Am Coll Cardiol 2013; 61: 2461-2467.

29 Redon J, Campos C, Narciso ML, Rodicio JL, Pascual JM, Ruilope LM. Prognostic value of ambulatory blood pressure monitoring in refractory hypertension: a prospective study. Hypertension 1998; 31: 712-718.

30 Muxfeldt ES, Salles GF. How to use ambulatory blood pressure monitoring in resistant hypertension. Hypertens Res 2013; 36: 385-389.

31 Hosohata K, Kikuya M, Ohkubo T, Metoki H, Asayama K, Inoue R, Obara T, Hashimoto J, Totsune K, Hoshi H, Satoh H, Imai Y. Reproducibility of nocturnal blood pressure assessed by self-measurement of blood pressure at home. Hypertens Res 2007; 30: 707-712.

32 Ishikawa J, Shimizu M, Sugiyama Edison E, Yano Y, Hoshide S, Eguchi K, Kario KJTOP (Japan Morning Surge-Target Organ Protection) Study Investigators Group. Assessment of the reductions in night-time blood pressure and dipping induced by antihypertensive medication using a home blood pressure monitor. J Hypertens 2014 32: 82-89.

33 Oikawa T, Obara T, Ohkubo T, Kikuya M, Asayama K, Metoki H, Komai R, Murai K, Hashimoto J, Totsune K, Imai Y. Characteristics of resistant hypertension determined by self-measured blood pressure at home and office blood pressure measurements: the J-HOME study. J Hypertens 2006; 24: 1737-1743.
34 Marui FR, Bombig MT, Francisco YA, Thalenberg JM, Fonseca FA, Souza D, Costa FA, Izar MC, Carvalho AC, Povoa R. [Assessment of resistant hypertension with home blood pressure monitoring]. Arq Bras Cardiol 2010; 95: 536-540.

35 Nasothimiou EG, Tzamouranis D, Roussias LG, Stergiou GS. Home versus ambulatory blood pressure monitoring in the diagnosis of clinic resistant and true resistant hypertension. J Hum Hypertens 2012; 26: 696-700.

36 Hermida RC, Ayala DE, Fernández JR, Mojón A, Smolensky MH, Fabbian F, Portaluppi F. Administration-time differences in effects of hypertension medications on ambulatory blood pressure regulation. Chronobiol Int 2013; 30 280-314.

37 Fadl Elmula FE, Hoffmann P, Fossum E, Brekke M, Gjonnaess E, Hjornholm U Kjaer VN, Rostrup M, Kjeldsen SE, Os I, Stenehjem AE, Hoieggen A. Renal sympathetic denervation in patients with treatment-resistant hypertension after witnessed intake of medication before qualifying ambulatory blood pressure. Hypertension 2013; 62: 526-532.

38 Fadl Elmula FE, Hoffmann P, Larstorp AC, Fossum E, Brekke M, Kjeldsen SE, Gjønnæss E, Hjørnholm U, Kjær VN, Rostrup M, Os I, Stenehjem A, Høieggen A Adjusted drug treatment is superior to renal sympathetic denervation in patients with true treatment-resistant hypertension. Hypertension (e-pub ahead of print 3 March 2014).

39 Turner JR, O'Brien E. Diagnosis and treatment of resistant hypertension: the critical role of ambulatory blood pressure monitoring. J Clin Hypertens (Greenwich) 2013; 15: 868-873.

40 Howard JP, Nowbar AN, Francis DP. Size of blood pressure reduction from renal denervation: insights from meta-analysis of antihypertensive drug trials of 4121 patients with focus on trial design: the CONVERGE report. Heart 2013; 99 1579-1587.

41 Weber MA, Black H, Bakris G, Krum H, Linas S, Weiss R, Linseman JV, Wiens BL, Warren MS, Lindholm LH. A selective endothelin-receptor antagonist to reduce blood pressure in patients with treatment-resistant hypertension: a randomised, double-blind, placebo-controlled trial. Lancet 2009; 374: 1423-1431.

42 Bakris GL, Lindholm LH, Black HR, Krum H, Linas S, Linseman JV, Arterburn S Sager $\mathrm{P}$, Weber M. Divergent results using clinic and ambulatory blood pressures: report of a darusentan-resistant hypertension trial. Hypertension 2010; 56: 824-830.

43 Persu A, Renkin J, Asayama K, O'Brien E, Staessen JA. Renal denervation in treatment-resistant hypertension: the need for restraint and more and better evidence. Expert Rev Cardiovasc Ther 2013; 11: 739-749.

44 Persu A, Azizi M, Burnier M, Staessen JA. Residual effect of renal denervation in patients with truly resistant hypertension. Hypertension 2013; 62: 450-452.

45 Mahfoud F, Ukena C, Schmieder RE, Cremers B, Rump LC, Vonend O, Weil J, Schmidt M, Hoppe UC, Zeller T, Bauer A, Ott C, Blessing E, Sobotka PA, Krum H, Schlaich M, Esler M, Bohm M. Ambulatory blood pressure changes after rena sympathetic denervation in patients with resistant hypertension. Circulation 2013, 128: $132-140$

46 Schmieder RE, Redon J, Grassi G, Kjeldsen SE, Mancia G, Narkiewicz K, Parati G, Ruilope L, van de Borne P, Tsioufis C. ESH position paper: renal denervation - an interventional therapy of resistant hypertension. J Hypertens 2012; 30: 837-841.

47 Schlaich MP, Schmieder RE, Bakris G, Blankestijn PJ, Bohm M, Campese VM, Francis DP, Grassi G, Hering D, Katholi R, Kjeldsen S, Krum H, Mahfoud F, Mancia G, Messerli FH, Narkiewicz K, Parati G, Rocha-Singh KJ, Ruilope LM, Rump LC, Sica DA, Sobotka PA, Tsioufis C, Vonend O, Weber MA, Williams B, Zeller T, Esler MD. International expert consensus statement: percutaneous transluminal renal denervation for the treatment of resistant hypertension. J Am Coll Cardiol 2013; 62: 2031-2045

48 Kandzari DE, Bhatt DL, Sobotka PA, O'Neill WW, Esler M, Flack JM, Katzen BT, Leon MB, Massaro JM, Negoita M, Oparil S, Rocha-Singh K, Straley C, Townsend RR, Bakris G. Catheter-based renal denervation for resistant hypertension: rationale and design of the SYMPLICITY HTN-3 Trial. Clin Cardiol 2012; 35: 528-535.

49 Doumas M, Anyfanti P, Bakris G. Should ambulatory blood pressure monitoring be mandatory for future studies in resistant hypertension: a perspective. J Hypertens 2012; 30: 874-876.

50 Persu A, Jin Y, Azizi M, Baelen M, Völz S, Elvan A, Severino F, Rosa J, Adiyaman A Fadl-Elmula $F E$, Taylor $A$, Pechère-Bertschi $A$, Wuerzner $G$, Jokhaji $F$, Kahan $T$, Renkin J, Monge M, Widimsky P, Jacobs L, Burnier M, Mark PB, Kjeldsen SE, Andersson B, Sapoval M, Staessen JA. Blood pressure changes after renal denervation at 10 European expert centers. J Hum Hypertens 2014; 28: 150-156.

$51 \mathrm{http}: / /$ guidance.nice.org.uk/CG127. Accessed 12 March 2014

52 http://www.sfhta.eu/wp-content/uploads/2012/07/Recommandation_HTA_re_sistante1-1.pdf. Accessed 12 March 2014 